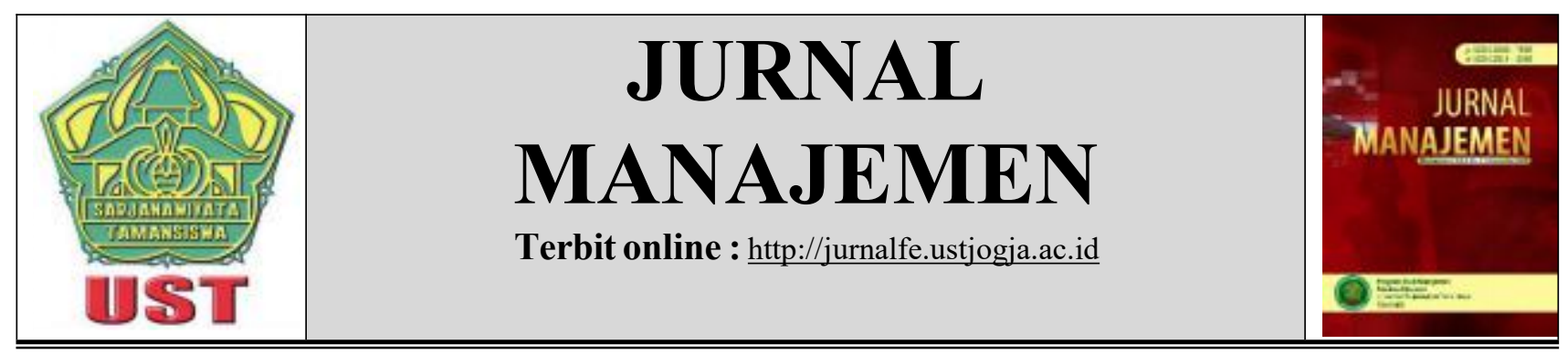

\title{
PENGARUH KUALITAS PELAYANAN TERHADAP KEPUASAN KONSUMEN MENGGUNAKAN JASA APOTEK FITRI TEMANGGUNG
}

\author{
Farruk Rastha Pradipta ${ }^{1,}$ \\ Rini Nurhidayati2, \\ Nur Wening ${ }^{3}$
}

1,2,3 Magister Manajemen, Universitas Teknologi Yogyakarta
Email: farrukrastha115@gmail.com

\begin{tabular}{lc}
\hline Informasi Naskah & Abstrak \\
\hline Diterima: 18 Oktober & This study aimed to see if there are service quality affects customer \\
$\mathbf{2 0 1 9}$ & satisfaction in using the services of Pharmacy Fitri Temanggung. Subjects \\
Revisi: 28 Oktober 2019 & in this study is that consumers Pharmacy Fitri Temaggung aged 18-60 \\
Terbit: 18 Desember 2019 & years; purchase drugs at private expense; able to read, write, and \\
\hline Kata Kunci: Customer & communicate well; and willing to fill out a questionnaire. \\
Satisfaction, Pharmacy & This study uses quantitative research methods, to determine the \\
Services, Service Quality,. & effect of service quality on consumer satisfaction using the services of the \\
& pharmacy Fitri Temanggung. The samples used in this study was 116 \\
& subjects. Measurements in this study was performed using a questionnaire \\
& based on the variables used. Data were analysed using classical assumption \\
& test and multiple regression analysis. \\
& Based on the analysis and discussion of the quality of service \\
& showed that the appearance of Pharmacy, Hospitality Officer, Drug \\
& Information Service at the pharmacy, Availability of Medicines in \\
& Pharmacies, Pharmacy Services and Speed affects customer satisfaction in \\
using Pharmacy Fitri Temanggung.
\end{tabular}

\section{PENDAHULUAN}

Apotek merupakan sarana kesehatan yang dibutuhkan oleh konsumen untuk mendapatkan obat. Menurut Peraturan Pemerintah (PP) 51 Tahun 2009, apotek merupakan sarana pelayanan kefarmasian dimana tempat dilakukan praktek kefarmasian oleh apoteker (Depkes, 2009). Perkembangan yang pesat telah terjadi di apotek dengan bergesernya orientasi seorang apoteker dari product atau drug oriented menjaadi patient oriented yang bertujuan untuk membantu konsumen memperoleh dan menggunakan obat yang tepat dan benar. Konsumen akan merasa puas jika kebutuhannya terpenuhi dengan baik.

Era globalisasi seperti sekarang ini berdampak pada produk atau jasa dalam satu pasar menjadi semakin bersaing akibat keterbukaan pasar, sehingga berakibat pada persaingan antar produsen dalam memenuhi kebutuhan konsumen serta kepuasan konsumen. Hal ini memicu setiap penyedia untuk terus bersaing mempertahankan kualitas produk ataupun jasa yang disediakan agar dapat mempertahankan pelanggan untuk tetap menggunakan produk ataupun jasa yang ditawarkan. Setiap konsumen selalu memiliki nilai kepuasan tersendiri terhadap penggunaan jasa ataupun produk suatu instansi atau perusahaan, mereka akan membandingkan antar instansi atau perusahaan 
yang telah mereka gunakan. Apabila konsumen merasa sangat puas, mereka akan membeli ulang bahkan merekomendasikan kepada orang lain untuk membeli di tempat yang sama. Berdasarkan hal tersebut, perusahaan harus mulai memikirkan pentingnya pelayanan kepada konsumen melalui kualitas pelayanan.

Kepuasan konsumen adalah situasi kognitif pembeli berkenaan dengan kesepadanan atau ketidaksepadanan antar hasil yang didapatkan dibandingkan dengan pengorbanan yang dilakukan (Howard dan Sheth, 1969). Kepuasan konsumen apotek merupakan cerminan dari kualitas pelayanan yang diberikan apotek, yang mana pelayanan tersebut dapat berupa interaksi dengan pelayanan medis, konsumen, atau sistem pelayanan kesehatan secara keseluruhan baik itu dari administrasi, keuangan, serta petugas apotek. Kepuasan konsumen menggunakan jasa apotek memiliki arti bahwa konsumen mengerti cara pemakian obat atau membeli produk tertentu di apotek (Angelova dan Zekiri, 2011). Artinya, kepuasan menggunakan jasa apotek merupakan sikap dari konsumen dalam menentukan arah dan tujuan akhir dalam proses memahami pemakaian obat secara tepat dan benar atau pembelian suatu produk obat, sehingga kepuasan konsumen menggunakan jasa apotek dapat digunakan sebagai tolak ukur untuk melihat seberapa besar kepuasan konsumen atas pelayanan yang diberikan.

Pelayanan merupakan peran penting dalam mencapai kepuasan konsumen, dimana apoteker mempunyai peran penting dan tanggung jawab dalam mewujudkan pelayanan yang berkualitas terhadap kepuasan konsumen. Pelayanan yang berkualitas menjadi tuntutan profesionalisme serta berfungsi untuk menarik minat konsumen terhadap pembelian obat di sebuah apotek. Meskipun demikian, untuk dapat tetap bertahan, setiap apotek berusaha untuk terus mempertahankan kualitas pelayanan. Kotler (2003) mengatakan bahwa pelayanan dapat didefinisikan sebagai suatu tindakan atau kinerja yang diberikan oleh seseorang kepada orang lain yang dapat diklasifikasikan menjadi High contact service dan Low contact service. Hasil penelitian yang telah dilakukan oleh Kondov, dkk (2015) adalah bahwa pelayanan yang berkualitas meliputi: kebersihan apotek, keramahan petugas, pelayanan informasi obat, ketersediaan obat, dan kecepatan pelayanan.

Idealnya, sebuah apotek dapat memberikan kepuasan yang sangat baik terhadap konsumen melalui pelayanan yang diberikan. Hal ini agar para konsumen tertarik untuk tetap menggunakan apotek tersebut sebagai pemenuh kebutuhannya. Banyak dapat kita jumpai apotek di lingkungan tempat tinggal, khususnya daerah yang berkembang hingga daerah maju. Sebagai contoh, Kabupaten Temanggung merupakan salah satu daerah berkembang. Telah terdapat banyak apotek di daerah ini sehingga sangat mudah bagi para konsumen untuk mendapatkan kebutuhan obat yang mereka inginkan, namun tidaklah semua apotek menjadi favorit untuk pilihan setiap masyarakat dalam membeli obat karena kepuasan konsumen akan berbeda pada setiap apotek yang dijumpainya.

Apotek Fitri Temanggung merupakan salah satu apotek yang tidak melayani jaminan kesehatan namun melayani pembelian obat resep dan non-resep, serta sangat mengutamakan kualitas pelayanan. Berdasarkan wawancara yang dilakukan terhadap pemilik Apotek Fitri Temanggung pada 17 Juli 2015, beliau mengatakan bahwa sebuah apotek memiliki kewajiban untuk memenuhi kebutuhan konsumen dalam hal kefarmasian untuk menunjang kesehatan para konsumen, sehingga Apotek Fitri sangat mengutamakan kualitas pelayanan agar para konsumen merasa puas dan tetap menggunakan Apotek Fitri Temanggung sebagai sarana tempat pembelian obat.

\section{KAJIAN PUSTAKA \\ Manajemen Operasi}

Manajemen operasional dapat diartikan sebagai suatu kegiatan yang berhubungan dengan pembuatan barang, jasa dan kombinasinya, melalui proses transformasi dari sumber daya produksi menjadi keluaran yang diinginkan (Herjanto, 2009). Rander dan Heizer (2009) menyatakan bahwa manajemen operasi adalah serangkaian aktivitas yang menghasilkan nilai dalam bentuk barang dan jasa dengan mengubah input menjadi output. Pendapat serupa disampaikan oleh Stevenson (2009) bahwa manajemen operasional adalah sistem manajemen atau serangkaian proses dalam pembuatan 
produk atau penyediaan jasa.

\section{Manajemen Kualitas}

Manajemen kualitas dapat dikatakan sebagai semua aktivitas yang menentukan kebijaksanaan kualitas, tujuan, dan tanggung jawab serta mengimplementasikan melalui alat-alat manajemen kualitas dari fungsi manajemen secara keseluruhan (Gaspersz, 2005). Total Quality Manajemen diartikan sebagai perpaduan semua fungsi dari perusahaan ke dalam falsafah holistic yang dibangun berdasarkan konsep kualitas, teamwork, produktivitas, dan pengertian serta kepuasan pelanggan (Ishikawa, 2005). Definisi lainnya menyatakan bahwa TQM merupakan sistem manajemen yang menyangkut kualitas sebagai strategi usaha dan berorientasi pada kepuasan pelanggan dengan melibatkan seluruh anggota organisasi (Santosa, 2007).

\section{Kualitas Pelayanan}

Kotler (2003) mengatakan bahwa pelayanan dapat didefinisikan sebagai suatu tindakan atau kinerja yang diberikan oleh seseorang kepada orang lain yang dapat diklasifikasikan menjadi High contact service dan Low contact service. Hasil penelitian yang telah dilakukan oleh Kondov, dkk (2015) adalah bahwa pelayanan yang berkualitas meliputi: kebersihan apotek, keramahan petugas, pelayanan informasi obat, ketersediaan obat, dan kecepatan pelayanan. Kualitas pelayanan dapat diartikan sebagai upaya pemenuhan kebutuhan dan keinginan konsumen serta ketepatan penyampaiannya dalam mengimbangi harapan konsumen (Tjiptono, 2007). Pujawan (2010:97) mendefinisikan kualitas pelayanan (service quality) sebagai hasil persepsi dan perbandingan antara harapan pelanggan dengan kinerja aktual pelayanan yang terdapat 2 faktor utama yang mempengaruhi kualitas jasa, yaitu expected service (pengalaman yang diharapkan) dan perceived service (pelayanan yang diterima). Sedangkan Mauludin (2010:67) mengemukakan bahwa kualitas pelayanan adalah seberapa jauh perbedaan antara kenyataan dan harapan pelanggan atas langganan yang mereka terima atau peroleh.

\section{Kepuasan Konsumen}

Kepuasan konsumen menurut Kotler (2003) adalah suatu respon berupa perasaan bahagia atau kecewa yang merupakan hasil dari membandingkan kesan konsumen terhadap kinerja ataupun hasil suatu produk terhadap harapan-harapannya. Howard dan Sheth (dalam Tjiptono, 2007) mengungkapkan bahwa kepuasan pelanggan adalah situasi kognitif pembeli berkenaan dengan kesepadanan atau ketidaksepadanan antar hasil yang didapatkan dibandingkan pengorbanan yang dilakukan. Kepuasan konsumen adalah tingkat perasaan konsumen setelah membandingkan antara apa yang dia terima dan harapannya (Umar, 2005:65). Sedangkan menurut Zulian Yamit (2005: 78) "Kepuasan konsumen merupakan evaluasi purna beli atau hasil evaluasi setelah membandingkan apa yang dirasakan dengan harapannya". Dalam konsep kepuasan konsumen, terdapat dua elemen yang mempengaruhi yaitu harapan dan kinerja.

\section{Hipotesis}

Terdapat pengaruh kualitas pelayanan Penampilan Apotek (X1), Keramahan Petugas (X2), Pelayanan Informasi Obat di Apotek (X3), Ketersediaan Obat di Apotek (X4), dan Kecepatan Pelayanan Apotek (X5) terhadap kepuasan konsumen menggunakan jasa Apotek Fitri Temanggung.

\section{METODE PENELITIAN}

Penelitian ini adalah jenis penelitian analitik dengan pendekatan Cross sectional (Woorfward, dalam buku Sastroasmoro dan Ismael, 2011). Peneliti dalam penelitian ini tidak melakukan intervensi atau perlakuan terhadap subjek penelitian, tetapi hanya memberikan kuesioner (self-administered). Penelitian ini menggunakan metode penelitian kuantitatif, untuk mengetahui pengaruh kualitas pelayanan terhadap kepuasan konsumen menggunakan jasa Apotek Fitri Temanggung. 
Metode analisis yang digunakan adalah regresi linier berganda yang disertai dengan pengukuran uji statistik t, uji statistik $\mathrm{F}$, dan uji koefisien determinasi. Analisis data juga didukung dengan pengujian asumsi klasik yang terdiri dari uji validitas dan reliabilitas, uji normalitas, uji autokorelasi, dan uji multikolinieritas.

\section{HASIL DAN PEMBAHASAN}

Hasil uji validitas menunjukkan bahwa seluruh aitem dalam instrumen yang digunakan dalam penelitian ini telah valid sebab memiliki r-hitung yang lebih besar daripada r-tabel. Berdasarkan hasil uji normalitas dengan Normal Probably Plot terlihat bahwa data mengikuti garis diagonal, maka model regresi telah memenuhi asumsi normalitas. Azwar (2010) mengatakan bahwa sejauh mana hasil suatu pengukuran dapat dipercaya hanya apabila dalam beberapa kali pelaksanaan pengukuran terhadap kelompok subjek yang sama diperoleh hasil yang relatif sama. Uji reliabilitas terhadap instrumen penelitian ini hanya dikenakan pada aitem-aitem yang telah memenuhi syarat validitas atau pada aitem-aitem yang lolos. Uji reliabilitas ini menggunakan teknik Alpha Cronbachdengan hasil sebagai berikut:

Tabel Hasil Uji Reliabilitas

\begin{tabular}{lccc}
\hline \multicolumn{1}{c}{ Variabel } & Cronbanch's Alpha & $\begin{array}{c}\text { Cronbach's Alpha } \\
\text { Based on } \\
\text { Standardized Items }\end{array}$ & N of Items \\
\hline $\begin{array}{l}\text { Penampilan apotek } \\
\text { Keramahan petugas }\end{array}$ & 0,84 & 0,84 & 17 \\
Pelayanan informasi & 0,95 & 0,95 & 6 \\
obat & 0,89 & 0,90 & 7 \\
Ketersediaan obat & 0,61 & 0,51 & 5 \\
Kecepatan pelayanan & 0,83 & 0,80 & 5 \\
Kepuasan konsumen & 0,90 & 0,90 & 5 \\
\hline
\end{tabular}

Berdasarkan hasil uji reliabilitas diketahui bahwa seluruh instrumen pada penelitian ini dapat dikatakan reliabel (nilai cronbanch's Alpha> 0,6) sehingga memenuhi syarat untuk digunakan sebagai alat ukur pengambilan data penelitian.

Hasil analisis mengenai pengaruh dari variabel Penampilan Apotek (X1), Keramahan Petugas (X2), Pelayanan Informasi Obat di Apotek (X3), Ketersediaan Obat di Apotek (X4), dan Kecepatan Pelayanan Apotek (X5) terhadap Kepuasan Konsumen (Y) menggunakan SPSS 17 diperoleh hasil sebagai berikut:

\section{Uji T (Parsial)}

Analisis ini digunakan untuk mengetahui ada atau tidaknya pengaruh variabel independen terhadap variabel dependen baik itu secara individual maupun parsial. Berdasarkan hasil olah data yang diperoleh, nilai koefisien $(X 1)=0,896,(X 2)=0,235$ dan $(X 3)=0,728$ yang berarti lebih kecil dari $\mathrm{T}$ tabel $(1,98)$ maka dari itu dapat disimpulkan bahwa tidak ada pengaruh dan tidak signifikan antara Penampilan Apotek (X1), Keramahan Petugas (X2), dan Pelayanan Informasi Obat Di Apotek (X3) Terhadap Kepuasan Konsumen Menggunakan Jasa Apotek Fitri Temanggung $(\mathrm{Y})$, sedangkan $(\mathrm{X} 4)=2,797$ dan $(\mathrm{X} 5)=5,287$ yang berarti lebih besar dari $\mathrm{T}$ table $(1,98)$, maka dapat disimpulkan bahwa Ketersediaan Obat Di Apotek (X4), Dan Kecepatan Pelayanan Apotek (X5) ada pengaruh yang signifikan Terhadap Kepuasan Konsumen Menggunakan Jasa Apotek Fitri Temanggung (Y). Hasilnya dapat dilihat pada tabel dibawah ini: 


\section{Tabel Hasil Uji T}

\begin{tabular}{|c|c|c|c|c|c|c|}
\hline \multirow[t]{2}{*}{ Model } & & \multicolumn{2}{|c|}{$\begin{array}{c}\text { Unstandardized } \\
\text { Coefficients }\end{array}$} & \multirow{2}{*}{$\begin{array}{c}\text { Standardized } \\
\text { Coefficients }\end{array}$} & \multirow[t]{2}{*}{$\mathrm{T}$} & \multirow[b]{2}{*}{ Sig. } \\
\hline & & $\mathrm{B}$ & Std. Error & & & \\
\hline \multirow[t]{6}{*}{1} & (Constant) & -7.942 & 3.970 & & -2.000 & .048 \\
\hline & X1 & .042 & .047 & .069 & .896 & .372 \\
\hline & $\mathrm{X} 2$ & .035 & .150 & .022 & .235 & .814 \\
\hline & $\mathrm{X} 3$ & .062 & .086 & .062 & .728 & .468 \\
\hline & $\mathrm{X} 4$ & .456 & .163 & .237 & 2.797 & .006 \\
\hline & $\mathrm{X} 5$ & .610 & .115 & .473 & 5.287 & .000 \\
\hline
\end{tabular}

a. Dependent Variable: Y

\section{Uji F (Serentak)}

Uji Statistik F digunakan untuk mengetahui apakah variabel independen mempunyai pengaruh secara simultan atau secara bersama-sama terhadap variabel dependen. Hipotesis yang diajukan adalah sebagai berikut:

\section{Tabel Hasil Uji F}

\begin{tabular}{lllllcr}
\hline & & \multicolumn{2}{c}{ Sum of } & & Mean & \\
Model & Squares & df & Square & F & Sig. \\
\hline 1 & Regression & 959.078 & 5 & 191.816 & 20.330 & $.000^{\mathrm{a}}$ \\
& Residual & 1037.845 & 110 & 9.435 & & \\
& Total & 1996.922 & 115 & & & \\
\hline
\end{tabular}

a. Predictors: (Constant), X1, X2, X3, X4, X5

b. Dependent Variable: Y

Pada tabel diatas dapat dilihat bahwa tingkat signifikannya adalah 0,000. Artinya adalah tingkat signifikansinya $<0,05$ sehingga dapat diambil kesimpulan bahwa secara simultan atau secara bersamaan variable dependen yaitu Penampilan Apotek (X1), Keramahan Petugas (X2), Pelayanan Informasi Obat Di Apotek (X3), Ketersediaan Obat Di Apotek (X4), dan Kecepatan Pelayanan Apotek (X5) berpengaruh signifikan terhadap Kepuasan Konsumen Menggunakan Jasa Apotek (Y).

\section{Uji Koefisien Determinasi}

Koefisien determinasi digunakan untuk mengukur seberapa kemampuan model dalam menerangkan variabel dependen. Nilai R2 yang kecil memberikan pengertian bahwa kemampuan variabel independen memberikan hampir semua informasi yang dibutuhkan untuk memprediksi variabel dependen.

\section{Tabel Uji Regresi Berganda}

\begin{tabular}{lccrr}
\hline \multicolumn{4}{c}{ Model Summary } \\
\hline Model & $\mathrm{R}$ & R Square & Adjusted R Square & $\begin{array}{c}\text { Std. Error of the } \\
\text { Estimate }\end{array}$ \\
\hline 1 & $.693^{\mathrm{a}}$ & .480 & .457 & 3.072 \\
\hline a. & Predictors: (Constant), X1, X2, X3, X4, X5 & & \\
\hline
\end{tabular}


Dari hasil regresi berganda diperoleh nilai R2 sebesar 0,48 yang berarti bahwa variabel Kepuasan Konsumen Mengunakan Jasa Apotek (Y) sebagai variabel dependen mampu dijelaskan oleh variabel independen yaitu Penampilan Apotek (X1), Keramahan Petugas (X2), Pelayanan Informasi Obat di Apotek (X3), Ketersediaan Obat di Apotek (X4), dan Kecepatan Pelayanan Apotek (X5) sebesar 48\% dan sisanya dijelaskan oleh variabel lain yang tidak masuk dalam penelitian ini.

Penelitian ini bertujuan untuk mengetahui pengaruh kualitas pelayanan terhadap kepuasan konsumen dalam menggunakan jasa Apotek Fitri Temanggung. Subjek dalam penelitian ini adalah konsumen Apotek Fitri Temaggung berusia 18-60 tahun; membeli obat dengan biaya pribadi; mampu membaca, menulis, dan berkomunikasi dengan baik; serta bersedia mengisi kuesioner. Sampel yang digunakan dalam penelitian ini adalah 116 subjek. Berdasarkan hasil uji normalitas didapatkan hasil bahwa kedua variabel menunjukkan data yang berdistribusi normal, valid, dan reliabel.

Penelitian ini juga menunjukkan hasil bahwa terdapat pengaruh kualitas pelayanan yang berdasar pada lima sub variabel, yaitu: Penampilan Apotek (X1), Keramahan Petugas (X2), Pelayanan Informasi Obat di Apotek (X3), Ketersediaan Obat di Apotek (X4), dan Kecepatan Pelayanan Apotek (X5) terhadap kepuasan konsumen menggunakan jasa Apotek Fitri Temanggung. Kelima sub variabel tersebut secara bersamaan memberikan kontribusi terhadap kepuasan konsumen sebesar $48 \%$.

Hasil tersebut memperkuat hasil temuan yang sebelumnya telah dilakukan oleh Trimurthy (2009) bahwa kelengkapan obat berpengaruh positif terhadap kunjungan konsumen dan Kurniawan (2012) bahwa kecepatan pelayanan berpengaruh terhadap kepuasan konsumen.

\section{PENUTUP}

\section{Kesimpulan}

Berdasarkan hasil analisis data dan pembahasan tentang kualitas pelayanan (penampilan apotek, keramahan petugas, pelayanan informasi obat di apotek, ketersediaan obat di apotek, dan kecepatan pelayanan apotek) terhadap kepuasan konsumen menggunakan jasa Apotek Fitri Temanggung dapat disimpulkan sebagai berikut:

1. Secara bersamaan variabel independen, yaitu Penampilan Apotek (X1), Keramahan Petugas (X2), Pelayanan Informasi Obat di Apotek (X3), Ketersediaan Obat di Apotek (X4), dan Kecepatan Pelayanan Apotek (X5) terhadap Kepuasan Konsumen Menggunakan Jasa Apotek (Y) berpengaruh signifikan terhadap Kepuasan Konsumen Menggunakan Jasa Apotek (Y).

2. Penampilan apotek (X1) berpengaruh tidak signifikan terhadap kepuasan konsumen menggunakan jasa Apotek Fitri Temanggung (Y).

3. Keramahan petugas (X2) tidak berpengaruh secara signifikan terhadap kepuasan konsumen menggunakan jasa Apotek Fitri Temanggung (Y).

4. Pelayanan informasi obat di apotek (X3) berpengaruh positif dan tidak signifikan terhadap kepuasan konsumen menggu- nakan jasa Apotek Fitri Temanggung (Y).

5. Ketersediaan obat di apotek (X4) berpengaruh signifikan terhadap kepuasan konsumen menggunakan jasa Apotek Fitri Temanggung (Y).

6. Kecepatan pelayanan apotek (X5) berpengaruh signifikan terhadap kepuasan konsumen menggunakan jasa Apotek Fitri Temanggung (Y).

\section{Saran}

Berdasarkan kesimpulan, hasil analisis data dan pembahasan yang diperoleh dalam penelitian ini, maka dianjukan saran-saran sebagai pelengkap terhadap hasil penelitian sebagai berikut: 
1. Bagi apotek yang memiliki standar kefarmasian yang baik mempertahankan pelayanan kefarmasian seperti penampilan apotek, pelayanan informasi obat, ketersediaan obat dan kecepatan pelayanan, agar dapat meningkatkan kepuasan pasien menggunakan jasa apotek.

2. Bagi apotek yang memiliki standar kefarmasian yang kurang baik untuk meningkatkan pelayanan seperti penampilan apotek, pelayanan informasi obat, ketersediaan obat, dan kecepatan pelayanan, agar dapat meningkatkan kepuasan pasien menggunakan jasa apotek.

3. Peningkatan jumlah kerja tenaga farmasi disesuaikan dengan beban kerja di apotek, sehingga faktor keramahan petugas dan kecepatan pelayanan akan dapat ditingkatkan.

4. Pihak apotek lebih meningkatkan profesionalisme tenaga farmasi agar dapat memberikan pelayanan kefarmasian yang baik khususnya pelayanan kesehatan tentang mengenai penggunaan obat yang rasional untuk meningkatkan kualitas kesehatan.

5. Penelitian ini diharapkan dapat digunakan sebagai acuan dalam perkembangan ilmu pengetahuan yang dapat membantu mewujud- kan pelayanan kesehatan yang bermutu khususnya pelayanan kefarmasian di apotek.

6. Peneliti selanjutnya dapat diharapkan dapat membahas secara lebih mendalam mengenai teoriteori yag dapat dijadikan acuan agar dapat melakukan pembahasan secara lebih merinci.

7. Peneliti selanjutnya dapat melakukan penelitian pada instansi lain untuk memperkuat hasil penelitian-penelitian sebelumnya.

\section{REFERENSI}

Angelova, B and Zekiri, J. 2011. Measuring Customer Satisfaction with Service Quality Using American Customer Satisfaction Model (Acsi Model). International Journal of Academic Research In Business And Social Sciences, Vol. 1, No. 3.

Azwar, A. 2010. Reliabilitas Dan Validitas. Yogyakarta: Andi

Departemen Kesehatan Republik Indonesia. 2009. Peraturan Pemerintah Republik Indonesia Nomor 51 Tahun 2009 Tentang Pekerjaan Kefarmasian. Depkes RI. Jakarta.

Gaspersz, Vincent. 2005. Total Quality Management. Jakarta: Gramedia Pustaka Utama.

Heizer, Jay, dan Rander, Bary. 2009. Manajemen Operasi Buku 1, Edisi 9. Jakarta: Salemba Empat. Herjanto, E. 2009. Manajemen Operasi Edisi Tiga. Jakarta: Grasindo.

Howard, J.A. dan Seth, J.N. 1969. The Theory of Buyer Behavior. New York: John Willey \& Sonds Inc.

Ishikawa, Khoru. (2005). Pengendalian Mutu Terpadu, Bandung: PT Remaja Rosdakarya

Kondov, Grace; Kansil, M.R; Umboh; Jootie.M.L. 2015. Hubungan Antara Pelayanan Kefarmasian Dengan Kepuasan Pasien Menggunakan Jasa Apotek di Kota Manado. Ejournal Usrat, Vol. 5, No.2.

Kotler, Philip. 2003. Marketing Manajemen 11th Edition. New Jersey: Prentice Hall.

Kurniawan, F . 2012. Kecepatan Waktu Pelayanan Rumah Sakit Berpengaruh Terhadap Kepuasan Pasien.

Mauludin, Hanif, 2010, Marketing Research: Panduan Bagi Manajer, Pimpinan Perusahaan Organisasi. Jakarta: Elex Media Kompitindo.

Pujawan, I., N. (2010). Supplay Chain Management. Surabaya: PT Guna Widya.

Santosa, Singgih. (2007). Total Quality Management (TQM) dan SixSigma. Jakarta: Media Komputindo.

Sastroasmoro Dan Ismael. 2011. Dasar-Dasar Metodologi Penelitian Klinis. Jakarta: Sagung Seto.

Stevenson, J., William. (2009). Operation Management. Mcgraw-Hill Irwin.

Tjiptono, Fandy. 2007. Strategi Pemasaran, Edisi Kedua. Yogyakarta: Andi.

Trimurthy, Iga. 2009. Analisis Hubungan Persepsi Pasien Tentang Mutu Pelayanan Dengan Minat Pemanfaatan Ulang Pelayanan Rawat Jalan Puskesmas Pandanaran Kota Semarang. (Tesis). Semarang. Universitas Diponegoro. 
Pradipta, Nurhidayati \& Wening/Jurnal Manajemen, Vol 9, No 2 (2019): 283 - 290

Umar, Husain. (2005). Riset Pemasaran \& Perilaku Konsumen. Jakarta: PT Gramedia Pustaka Utama.

Yamit, Zulian. (2005). Manajemen Produksi \& Operasi. Jakarta: Ekonesia. 